\title{
AUXÍLIO DIRETO: UMA COOPERAÇÃO INTERNACIONAL NO COMBATE À LAVAGEM DE ATIVOS E OS CRIMES QUE A ANTECEDEM
}

\author{
Letícia Gabriela Camargo Franco de Lima ${ }^{1}$ \\ Sandra Maciel-Lima ${ }^{2}$
}

\begin{abstract}
RESUMO
Contextualização: O processo penal precisa se adaptar ao mundo globalizado e aperfeiçoar as técnicas investigativas, sob pena de se tornar inoperante com relação à macrocriminalidade representada por crimes que geram consequência s globais e se concretizam muitas vezes a part ir da utilização do sistema financeiro de diversos países. Objetivo: O objetivo do artigo é analisar o auxílio direto, procedimento investigativo que propicia o diálogo, auxílio e compartilhamento de provas transnacional, previsto no Código de Processo Civil de 2015. Pretende-se verificar a necessidade de cooperação interna entre órgãos fiscaliza tórios, poder judiciário e empresas privadas por mecanismos de compliance para efetividade punitiva. Método: O presente artigo utiliza a abordagem qualitativa; quanto ao procedimento técnico, utiliza a pesquisa bibliográfica, mediante revisão de artigos científicos rea liza dos sobre o tema no Google Scholar, no período de 2018 à 2020, com os descritores "persecução penal", "cooperação interna cional" e "crimes financeiros; assim como, revisão da legislação relacionada ao tema. Resultados: As pesquisas realizadas contribuíram na verificação de que a solução para o melhor desenvolvimento investigatório e sancionador da macrocriminalidade econômica é isolar países não cooperantes buscando em última medida a proibição de relacionamento financeiro com os demais Estados, medidas que já vem sendo orientadas por organismos intergovernamentais. Conclusões: Observou-se que os órgãos fiscalizatórios e os procedimentos a dotados ca minham em direção ao compartilha mento de provas e auxílio interna cional expandindo o alcance da investigação, porém ainda existem paraísos fiscais que impedem o aperfeiçoamento do sistema punitivo.
\end{abstract}

Palavras-chave: Persecução Penal; Cooperação Internacional; Crimes Financeiros; Auxílio-direto; Compliance

Submetido em: 16/12/2020

Aprovado em: 01/06/2021

DOI: https://doi.org/10.37497/revcampojur.v9i1.724

\footnotetext{
${ }^{1}$ Mestranda pelo Programa de Mestrado e Doutorado em Direito Empresarial e Cidadania - UNICURITIBA, Paraná (Brasil). Orcid: http://orcid.org/0000-0003-4286-5929. Email: leticiagcflima@ outlook.com.br

2 Doutora. Pesquisadora e Docente do Programa de Mestrado e Doutorado em Direito Empresarial e Cidadania UNICURITIBA, Paraná (Brasil). Orcid: http://orcid.org/0000-0002-5917-6540 Email: maciellima.sandra@ gmail.com.
} 


\title{
DIRECT AID: INTERNATIONAL COOPERATION AGAINST LAUDERING OF ASSETS AND THE CRIMES THAT PRECEDE IT
}

\begin{abstract}
Background: The criminal process needs to adapt to the globalized world and improve investigative techniques, otherwise it becomes inoperative in relation to the macro-crime represented by crimes that generate global consequences and are often rea lized through the use of the financial system of different countries. Objective: The objective of the article is to analyze direct assistance, an investigative procedure that provides transnational dialogue, assistance and sharing of evidence, provided for in the 2015 Code of Civil Procedure. and private companies through compliance mechanisms for punitive effectiveness. Method: This article uses a qualitative approach; as for the technical procedure, it uses bibliographic research, by reviewing scientific articles on the subject in Google Scholar, from 2018 to 2020, with the descriptors "criminal persecution", "international cooperation" and "financial crimes; as well as review of legislation related to the subject. Results: The surveys carried out contributed to verifying that the solution for the best investigative and sanctioning development of economic macrocrime is to isolate non-cooperating countries, ultimately seeking to prohibit financial relationships with other States, measures that have already been guided by intergovernmental bodies. Conclusions: It was observed that the inspection bodies and the procedures adopted move towards the sharing of evidence and international assistance, expanding the scope of the investigation, but there are still tax havens that impede the improvement of the punitive system.
\end{abstract}

Keywords: Criminal Prosecution; InternationalCooperation; FinancialCrimes; Direct aid ; Compliance

\section{INTRODUÇÃO}

A criminalidade moderna é marcada por um contexto global no qual as ações criminosas e seus efeitos recaem sobre diversas nações, gerando vítimas difusas e acarretando um impacto financeiro negativo mundial.

Segundo Gomes (apud MAGALHÃES, 2018, p. 47) "A criminalidade que marca o mundo contemporâneo globalizado é a macro criminalidade, que segund o Luiz Flávio Gomes é um conceito que abrange a geração de grandes danos a vítimas concretas ou difusas".

A influência da globalização sob a criminalidade proporcionou a eliminação do controle das fronteiras, tornando impossível que o Estado controlasse as diversas transações financeiras entre nações, permitindo condições de aperfeiçoamento e facilitando delitos, especialmente contra a economia (ZANON, 2019, p.17).

A lavagem de ativos surge dentro desse contexto justamente porque está intimamente ligada a troca instantânea de informações, tecnologias e facilitada ainda mais pelo ambiente virtual das transações bancárias (CANESTRARO, 2018, p. 3).

Entendendo o aspecto global que envolve as modernas práticas criminosas Moro (2010, p. 23) já advertia que "Se o crime é transnacional, não haverá investigação e persecução eficaz restrita às fronteiras nacionais." 
Nesse sentido também, Magalhães (2018, p. 44) destaca que conforme a humanidade se integra perpassando fronteiras, surge a necessidade da integração ou ao menos da harmonização entre os ordenamentos jurídicos.

Reconhecendo a importância da cooperação jurídica internacional como meio necessário no combate à criminalidade moderna e em um mundo globalizado, diversas pesquisas científicas tem buscado aprofundar os estudos dos mecanismos que propiciam o diálogo, o auxílio investigativo e o compartilhamento de provas transnacional.

Espera-se que o presente artigo contribua na averiguação do engajamento global no combate aos crimes econômicos modernos, buscando apurar os problemas ainda existentes na seara investigativa e os benefícios que o auxílio direto traz nesse contexto.

\section{PROCESSO METODOLÓGICO}

Para atingir o objetivo deste artigo foi feito um estad o da arte a partir do Google Scolar, utilizando-se os descritores "Persecução Penal”, "Cooperação Internacional” e "Crimes Financeiros" no período 2018-2020. Este período reflete um contexto jurídico nacional avançado no combate à criminalidade marcado por um intenso avanço probatório decorrente dos resultados obtidos com a operação Lava Jato. Além desta base de dados, optou-se pela pesquisa bibliográfica e análise do ordenamento jurídico nacional sobre o procedimento do Auxílio Direto.

Através do estado da arte foi possível encontrar 121 artigos, dos quais selecionou-se quatorze, devidamente identificados nas referências e que se relacionam intimamente com o presente estudo.

Por meio de pesquisa bibliográfica investigou-se também, a legislação e a doutrina que versam sobre o Auxílio Direto, procedimento previsto no artigo 28 e seguintes do Código de Processo Civil (CPC), assim como de que modo ele colabora para a troca de informações entre as Nações no enfrentamento à lavagem de ativos e a macro criminalidade antecedente que muitas vezes é também marcada pelo contexto transnacional.

\section{LAVAGEM DE ATIVOS E CRIMES ANTECEDENTES - NECESSIDADE DE COOPERAÇÃO INTERNACIONAL}

O crime de lavagem de ativos está previsto na Lei 9.613/98 (BRASIL, 1998) e conforme explica Soares (2020, p.5-6) define-se como um crime intimamente relacionado a 
outros, pois visa dissimular valores provenientes de delitos penais. Explica o autor que a legislação nacional é considerada moderna haja vista que a Lei 12.683/12 (BRASIL, 2012) abriu espaço para que qualquer crime possa ser considerado delito antecedente da lavagem de ativos, inexistindo um rol taxativo previsto.

A eliminação do rol de crimes antecedentes, junto com alterações no rol de destinatários reflete o objetivo central da legislação que visou aproximar o direito interno das recomendações internacionais sobre o tema. (SOBREIRA FILHO; REIS; EMERICH, 2019, p.5)

Inicialmente, analisando as características da lavagem de dinheiro, a necessidade da cooperação internacional já se torna evidente. Callegari e Weber (2017, p. 15) elencam em sua obra as principais: Internacionalização das atividades de lavagem; profissionalização do trabalho; vocação de permanência; complexidade ou variedade dos métodos; volume do fenômeno e a conexão entre redes criminais. Dentre elas, explicam que a característica de internacionalização dificulta a persecução do crime e facilita sua ocultação em razão da deficiência de coordenação internacional na luta contra a lavagem pois apesar de haver uma crescente nas medidas preventivas, deve-se reconhecer as lacunas aind a existentes.

Cordero (apud CALLEGARI; WEBER, 2017, p. 15) afirma que a internacionalização do crime, além de permitir aos lavadores de dinheiro que se beneficiem dos problemas de cooperação entre Estados, os auxilia na escolha de países com regras permissivas, sem rigoroso compromisso com políticas de controle e combate criminal, além de poder utilizar países com falhas de regulamentação para destinação dos bens e objeto de lavagem.

A lavagem de ativos é facilmente identificada como delito transnacional, que segundo Davin (apud GALÍCIA, 2018, p.48) possui como características a sofisticação, intensa troca de informações e vale-se de oportunidades criminais de ordem global, tudo isso gerenciado de forma organizada objetivando aumentar o rendimento do crime e minimizar o risco de confisco dos bens.

Reconhecendo o atual panorama globalizado da criminalidade Moriyama (2018, p.3540) aponta as principais deficiências dos mecanismos probatórios existentes. Começando pela delação premiada, que pode induzir o Estado ao erro, confundindo as investigações, forjando provas e manipulando informações. Moro (2010, p. 111) reconhecendo a reduzida confiabilidade da palavra de um criminoso traça 02 regras para o aproveitamento do depoimento, a primeira é a necessidade de que o depoimento seja corroborado por provas independentes e a segunda é que o depoimento deve proporcionar a escalada da investigação, 
ou seja, fazer um acordo com um criminoso pequeno objetivando a prova contra o grande ou contra vários outros integrantes da organização.

Sob este prisma Moriyama (2018, p.35-40) aponta também que a gravação ambiental é um instituto que enfrenta problemas técnicos e obstáculos como sinais, obtenção de dados e custos. Conforme acentua Moro (2010, p. 115), as dificuldades do método relacionam-se ainda com a descoberta do local que será planejado o crime e a forma de ingresso para colocação do dispositivo eletrônico de forma segura.

No que toca à ação controlada Moriyama (2018, p.35-40) ressalta a falta de parâmetros de aplicação e execução que atualmente têm sido amenizados apenas por critério judicial no caso concreto. Afirma ainda que a infiltração de agentes é permeada de riscos ao agente infiltrado e que a falta de parâmetros pré-definidos sobre os limites de suas ações, é um fator que dificulta inclusive o aspecto moral do instituto.

Já quanto a interceptação telefônica e a quebra de sigilo bancário Moriyama (2018, p.35-40) menciona que são modalidades que enfrentam dificuldades enquanto possíveis causad oras de ofensa à direitos de privacid ade e intimidade. Nesse sentido, ad verte Moro (2010, p. 106-107) que quanto maior a intromissão na esfera privada, maior o nível de prova que será exigido para a autorização judicial do método investigativo.

A partir dessa análise, Moriyama (2018, p.40) identifica um problema sistêmico eis que o sistema probatório ainda é muito tímido, faltando mecanismos de colheita de prova que inovem dos já trazidos em 2013 na Lei 12.850 (BRASIL, 2013), a qual trata das organizações criminosas.

Compartilhando desse entendimento Moro (2010, pg. 100), defende duas estratégias possíveis como saída para essa deficiência probatória: “a) a criação de regras probatórias compatíveis com as dificuldades, e/ou b) o incremento dos meios de investigação disponíveis às autoridades públicas."

$\mathrm{Na}$ análise sobre eficácia probatória Moro (2010, p. 131) defende ainda que um objetivo político que se impõe, caso se pretenda alguma eficácia no combate aos crimes modernos complexos como a criminalidade econômica, é a cooperação institucional internacional através do compartilhamento de informações.

O alcance da cooperação internacional conforme pesquisa de Silva (2018, p.20) compreende "os mais variados atos públicos, ou seja, em sentido lato sensu, versando sobre medidas legislativas, administrativas e judiciais, decisórias ou não”. A pesquisa ainda identifica 
que apesar de não haver um procedimento específico, a cooperação internacional já estava autorizada quando da elaboração da Constituição Federal/88 (SILVA, 2018, p.23). ${ }^{3}$

A pesquisa realizada por Silva (2019, p.23) focou no estudo das organizações criminosas transacionais e concluiu que o controle do crime organizado transacional depende não só de uma legislação internacional unificada mas da verdadeira integração entre as nações, compreendendo as agências de governo, cidadãos, e Estados formando uma política de segurança pública internacional empenhada na prevenção e combate da macro-criminalidade.

A cooperação internacional tem se manifestado não apenas através de procedimentos processuais mas também por meio de convenções, acordos, organizações e outras formas de políticas públicas.

Zanon (2019, p.49) por sua vez, destaca a Convenção de Viena, estabelecida em 1988, para combater o tráfico ilícito de entorpecentes que definiu também o crime de lavagem de dinheiro que hoje é reconhecido mundialmente. Identificou ainda a criação do GAFI - Grupo de Ação Financeira contra a Lavagem de Dinheiro e Financiamento ao Terrorismo, uma organização intergovernamental que visa o desenvolvimento de políticas nacionais e internacionais no combate à lavagem de dinheiro e ao Financiamento do terrorismo. Entre os principais objetivos do GAFI, Sobreira Filho; Reis; Emerich (2019, p.11) ressaltam a padronização dos métodos de controle da lavagem de ativos dos países contando com 26 representantes de governos incluindo centros financeiros de destaque mundial.

Seguindo a ordem cronológica do surgimento de sistemas internacionais de combate ao crime organizado transnacional a pesquisa de Zanon $(2019$, p.50) nos remete à Convenção da Organização para a Cooperação e Desenvolvimento Econômico (OCDE) celebrada em 1990 que tratou sobre suborno de funcionários públicos em transações comerciais internacionais, bem como a Convenção Interamericana firmada em 1996 caracterizada por mecanismos de prevenção, investigação, punição e erradicação da corrupção.

Em 1995 foi criado o grupo Egmont, que constitui um organismo internacional composto pelas chamadas Unidades deInteligência Financeiras, que segundo Magalhães (2018, p. 167) têm três funções básicas que visam auxiliar no processo de investigação penal: Primeiro recebe as comunicações das operações suspeitas de lavagem de ativos enviadas por agentes econômicos; posteriormente analisa os dados mediante cruzamento com outras informações e

\footnotetext{
3 Art. $4^{\circ}$ A República Federativa do Brasil rege-se nas suas relações internacionais pelos seguintes princípios: [...] IX - cooperação entre os povos para o progresso da humanidade; [...]. (BRASIL, 1988).
} 
por fim repassa relatórios minuciosos sobre indivíduos e operações suspeitas aos órgãos de persecução criminal.

Numa perspectiva de fortalecimento institucional sobreveio em 2003 a Convenção de Mérida que buscou também estimular a sociedade civil no engajamento ao processo anticorrupção. Seguindo, em 2006 a Estratégia Nacional de Combate à Corrupção e à Lavagem de Ativos (ENCCLA), foi constituída para formular políticas públicas pensadas e organizadas por instituições diversas (ZANON, 2019, p.52).

Como panorama geral, Galícia (2018, p.57) apresenta algumas premissas para configuração da cooperação internacional: “(i) interação entre diferentes Estados, (ii) fundada na voluntariedade e reciprocidade, (iii) utilizando-se de mecanismos de comunicação ou execução transnacionais, (iv) a serviço da persecução penal."

Assim, diante do vasto compromisso internacional no combate à criminalidade econômica moderna, efetivado por tratados e convenções que estimulam o compartilhamento de provas, torna-se de extrema relevância averiguar um dos procedimentos utilizados pelo Brasil na cooperação investigativa: o Auxílio Direto.

\section{AUXÍLIO DIRETO - CARACTERÍSTICAS PROCEDIMENTAIS}

O Código de Processo Civil de 2015 (BRASIL, 2015) trouxe um procedimento moderno para viabilizar a cooperação internacional chamado de Auxílio Direto. Referido procedimento está previsto em primeiro lugar no capítulo “da cooperação internacional” e é seguido pela Carta Rogatória, outra forma de cooperação jurídica internacional já utilizada há tempos e da homologação de sentença estrangeira prevista no artigo 960.

A cooperação internacional através do Auxílio Direto tem por objeto não apenas o compartilhamento de provas, mas um amplo auxílio investigativo e processual evidenciado pelo rol exemplificativo do artigo 30 do CPC que prevê a: I - obtenção e prestação de informações sobre o ordenamento jurídico e sobre processos administrativos ou jurisdicionais find os ou em curso; II - colheita de provas, salvo se a medida for adotada em processo, em curso no estrangeiro, de competência exclusiva de autoridade judiciária brasileira; III - qualquer outra medida judicial ou extrajudicial não proibida pela lei brasileira (BRASIL, 2015).

Segundo informações do Ministério da Justiça o Brasil é um país eminentemente demandante de cooperação jurídica internacional haja vista mais de $80 \%$ de todos os pedidos de cooperação referirem-se a demandas de Autoridades brasileiras para o exterior (BRASIL, 
2020). Tal fato revela a necessidade do auxílio transnacional como forma de efetivar a justiça em uma escala global.

Conforme roteiro de tramitação exposto pelo Ministério da Justiça, o Auxílio direto pode ser realizado com base em tratado internacional ou em garantia de reciprocidade para casos análogos. Em ambos os casos as Autoridades Centrais ficarão encarregadas de apresentar e receber, normalmente por comunicação direta entre elas, os pedidos de auxílio jurídico direto.

Segundo Polido (2018, n./p.) as Autoridades Centrais "representam os órgãos de enlace, tramitação e comunicação de atos e pedidos de cooperação e assistência jurisdicional e administrativa, estabelecidos em tratados, por designação dos Estados.” O CPC no art. 26, § $4^{\circ}$ (BRASIL, 2015), estabelece uma regra supletiva quando inexistente em âmbito de tratados e convenções processuais internacionais outro órgão competente, evidenciando a responsabilidade do Ministério da Justiça: “\$4 O Ministério da Justiça exercerá as funções de autoridade central na ausência de designação específica.” (BRASIL, 2015)

O principal objetivo do auxílio direto segundo Polido (2018, n./p.) é o de simplificar e agilizar a cooperação internacional. Nesse aspecto, o autor observa que a redação do artigo 28 do Código de Processo Civil traz regra que facilita e torna célere o procedimento justamente pois a medida solicitada independerá de juízo de delibação para cumprimento, pois destinada a ser cumprida segundo uma obrigação internacional prevista em tratado: "Cabe auxílio direto quando a medida não decorrer diretamente de decisão de autorid ade jurisd icional estrangeira a ser submetida a juízo de delibação no Brasil.” (BRASIL, 2015)

Sobre o aspecto procedimental Squeff (2017) explica que haverá diferenças dependendo de qual Autoridade Central pleiteia o auxílio na prestação jurisdicional: na Cooperação ativa, os atos públicos solicitados serão alcançados no exterior, enquanto na Cooperação Passiva os atos públicos demandados são consumados no plano interno. Ainda, quanto a natureza do pedido de auxílio, o procedimento também diverge dependendo se administrativo ou judicial.

Se a cooperação jurídica internacional for ativa, o trâmite processual se iniciará com a verificação dos requisitos de admissibilidade do Auxílio Direto pelo Departamento de Recuperação de Ativos e Cooperação Jurídica Internacional (DRCI) que integra o Ministério da Justiça e exerce a função de Autorid ade Central (LEMOS \& ZAGANELLI, 2018, p. 101).

Analisand o o preenchimento dos requisitos de admissibilid ade, autenticidade e clareza do pedido - art. 29 CPC - o DRCI encaminhará o pedido à Autoridade Central do país requisitado. Lemos e Zaganelli (2018, p. 102) advertem que os documentos enviados devem 
estar traduzidos para que na sequência, conforme rito interno do país requisitado seja o pleito encaminhado ao órgão judiciário responsável pelo processamento e execução da diligência solicitada.

Neste mesmo diapasão Lemos e Zaganelli (2018, p. 102) explicam ainda que na ausência de tratados e convenções, para que o auxílio internacional ocorra dependerá de meios diplomáticos, sendo que a transação de informações e mútua colaboração ocorrerá através das competências do Ministério das Relações Exteriores brasileiro e da representação brasileira no exterior (consulado) que remeterá o pedido à entidade responsável no país de modo a perseguir os trâmites internos.

Quanto à cooperação passiva, o procedimento está previsto nos artigos 32 a 34 do CPC/2015 que estabelecem o dever da Autoridade Central adotar as providencias para o cumprimento quando o auxílio decorrer de atos que não necessitam de prestação jurisdicional. Lemos e Zaganelli (2018, p. 102) esclarecem que quando o pedido de cooperação passiva não depender de provimento judicial, mas apenas de atos de cunho administrativo, a Autoridade Central tem a possibilidade de encaminhar a diligência à Coordenação Geral de Polícia Criminal Internacional do Departamento de Polícia Federal para respectiva análise e cumprimento.

No entanto, caso necessite de decisão judicial, caberá à Autoridade encaminhar à Advocacia Geral da União (AGU) o pedido de Auxílio Direto, a qual requererá em juízo a medida solicitada. Conforme art. 34 do CPC, caberá ao juízo federal do lugar em que deva ser executada a medida apreciar o pedido que demanda a prestação de atividade jurisdicional (BRASIL, 2015).

Aduzidos autores Lemos e Zaganelli (2018, p. 96-97) destacam que com o auxílio direto a persecução penal tem um colaborador estrangeiro, funcionando como "longa manus" dos legitimados nacionais (Polícia Judiciária, Ministério Público Federal, Justiça Federal, dentre outros) na investigação, sendo que a remessa dos fatos ao judiciário estrangeiro acarretará além da decisão judicial a própria execução ou não da decisão.

Soares (2020, p.12) ressalta que novamente, a peça chave para trazer a justiça esperada e que fica evidente nesse procedimento é a comunicação, pois em um mundo onde as transferências de valores são instantâneas a demora na persecução refletirá em impunidade. Segundo o autor, "Essa troca de informações entre órgãos nacionais e internacionais é o fator que multiplica as possibilidades de se obter sucesso na persecução penal.” 
Apesar dos avanços proporcionados à investigação, Lemos e Zaganelli (2018, p. 97) traçam críticas ao instituto no tocante a paridade de armas processual, já que a defesa do investigado não encontra guarida nos diversos tratados internacionais que lhe possibilite perquirir também elementos de prova com a cooperação internacional decorrente do auxílio direto. Tal restrição é materializada ainda pelo Mutual Legal Assistence Treaty (MLAT) Brasil/EUA e no protocolo de São Luís, representando grave violação à ampla defesa.

Essa já era uma preocupação em âmbito interno e agora também faz parte do problema central internacionalmente, já que o ideal é o alcance do equilíbrio, ou seja, uma persecução penal rápida e efetiva mas que não deixe de observar as garantias individuais do investigado tanto em âmbito nacional quanto internacionalmente (GALÍCIA, 2018 p.44)

Todo esse procedimento que buscou adequar-se as características globais da criminalidade moderna visa enfrentar não apenas o crime em si, mas os resultados sociais e econômicos que ocasiona mundialmente. Assim, necessário verificar quais as finalidades do procedimento, para além de uma cooperação formal entre Estados.

\section{DAS FINALIDADES DO AUXÍLIO DIRETO}

O Auxílio Direto utilizado para unir as Nações, facilita a aplicação de mecanismos investigativos que além de identificar os Autores do delito visa impedir a perpetuação da atividade criminosa através de prevenção e enfrentamento na persecução penal.

Magalhães (2018, p. 136) ressalta que o enfoque deve ser na criação de empecilhos da compensação criminosa, em suas palavras "a atividade criminosa menos atrativa à medida que se procura obstruir a fruição da vantagem econômica auferida pelo delinquente."

O Autor basicamente evidencia o fato de que enquanto o crime compense em função da desproporcionalidade entre o valor econômico que atrai e as baixas condenações impostas, esse cenário de criminalidade em larga escala não mudará.

Para que haja eficácia na prevenção, impõe-se a investigação, bloqueio e apreensão do lucro do delito e isso só é possível quando as ações investigativas atuarem tanto na atividade principal quanto no resultado desta atividade ilícita, visando tornar custoso o alcance da vantagem. (OLIVEIRA, 2018, p.210)

Pinotti et al. (2019, p. 18) analisando o sistema punitivo brasileiro afirma que os grandes índices de criminalidade vividos por uma sociedade decorrem justamente dos 
incentivos para a conduta criminosa, eis que o ganho fácil e de grandes proporções é usufruído mediante baixos riscos de punibilidade.

Segundo Magalhães (2018, p. 138) os esforços em localizar os fundos ilícitos através de rastreamento do dinheiro levará inexoravelmente à identificação dos comandantes das organizações criminosas, de forma que com apenas um procedimento os resultados são duplicados.

Desse modo enfatiza Silva (2018, p. 42) que o auxílio internacional deve ter esse olhar de enfoque no crime de lavagem de ativos - bens e dinheiro - ou seja, retirar a razão do crime. Em suas palavras: “um delito que não obtém sucesso em desviar o capital ilícito está propenso a fracassar."

Assim os mecanismos e órgãos nacionais devem estar compromissados na criminalização, prevenção, investigação e punição dos delitos econômicos de modo que a cooperação ativa e passiva através do auxílio direto produzam os resultados esperados ao final do processo.

Magalhães (2018, p. 169) aborda sobre a estrutura nacional brasileira na prevenção e repressão do crime de lavagem de ativos, explicando que sobre as funções das principais instituições. Segundo o Autor, o COAF - Conselho de Controle de Ativos Financeiros é um órgão integrante do Ministério da Justiça que juntamente com o BACEN - Banco Central do Brasil, possui função administrativa para fiscalizar instituições financeiras.

Neste ponto compete salientar que a atuação fiscalizatória do COAF, respaldada pela Lei $n^{\circ}$ 9.613/98 é somente ind ireta já que essa função de forma direta é exercida pelo BACEN que detém o controle de crédito, poder fiscalizatório e de autorização do funcionamento de instituições financeiras, vigia interferência de empresas no mercado financeiro entre outras atividades regulamentadas na Lei 4.595/64. (SOBREIRA FILHO; REIS \& EMERICH, 2019 p.6-7)

Portanto, como autorid ade administrativa encarregada do poder fiscalizatório, o Banco Central editou normas no intuito de prevenir, verificar a qualidade dos procedimentos preventivos de ilícitos contra o sistema financeiro já implantados e assegurar o cumprimento da Lei:

[...] as instituições financeiras e demais instituições sob sua regulamentação devem manter atualizados os ca dastros dos clientes; manter controles internos para verificar, a lém da a dequada identificação do cliente, a compa tibilida de entre as correspondentes movimentações de recursos, atividade econômica e capacidade financeira dos usuários do sistema financeiro nacional; manter registros de operações; comunicar operações ou situações suspeitas a o Banco Central; promover treinamento para seus 
empregados e; implementar procedimentos internos de controle para detecção de operações suspeitas. (SOBREIRA FILHO; REIS \& EMERICH,2019 p.12-13)

A Comissão de Valores Imobiliários (CVM), a Secretaria de Previdência Complementar e a Superintendência de Seguros Privados (Susep) também integram o sistema nacional de combate a lavagem de ativos pois atuam, respectivamente, na fiscalização de corretoras de títulos imobiliários e bolsas de valores; entidades fechadas de previdência privada e fundos de pensão; e empresas de seguro e capitalização (MAGALHÃES, 2019, p. 170).

Entre os órgãos com competência antilavagem, o autor menciona ainda a Estratégia Nacional de Combate à Corrupção e à Lavagem de Dinheiro (ENCCLA): “que possui o objetivo de avaliar e propor medidas de aprimoramento do sistema institucional e normativo antilavagem"; o Departamento de Recuperação de Ativos e Cooperação Jurídica Internacional, que visa "estabelecer relações com os Estados e organizações internacionais para a reinternalização de fundos ilícitos enviados ao exterior” e os Laboratórios de Tecnologia contra a Lavagem de Dinheiro, responsável pelo "cruzamento de informações financeiras e análise das comunicações de operações suspeitas recebidas pelas autoridades regulatórias buscando efetivar o mecanismo investigativo de rastreamento dos recursos ilícitos". (MAGALHÃES, 2019, p. 171).

Além de um sistema institucional efetivo e compromissado, necessário também que o sistema de justiça criminal esteja focado para que então todo o auxílio realizado gere responsabilidades e restrinja o nível de compensação da conduta criminal. Neste âmbito, Pinotti et al. (2019, p. 199) enfatizou que a Lava Jato representou uma mudança de paradigma, quebrando uma tradição de impunidade que contribuía para a corrupção sistêmica.

Como precedente judicial Pinotti et al. (2019, p. 206) evidenciou o julgamento do Habeas Corpus (HC) 126292 como a mais importante decisão do Supremo Tribunal Federal que alterou a regra da impunidade que era estabelecida pela exigência de trânsito em julgado para a execução da condenação:

\footnotetext{
É possível que o tribunal tenha sido influenciado pelas revelações trazidas pela Lava Jato e pela percepção da maioria dos ministros de que a exigência de transito em julgado, embora travestida de garantia, representava um privilégio de impunidade para criminosos poderosos, os mesmos que estavam sendo acusados na opera ção. Com isso fechou-se a principal brecha do sistema processual penal que era utilizada, com frequência, por criminosos poderosos para evitar que fossem responsabilizados por seus crimes, ainda que fossem graves, e as provas, cabais.
}

Outro precedente importante no enfrentamento da criminalidade organizada, que também pode ser considerado como forma de reduzir de forma significativa os incentivos aos 
ilícitos é o julgamento do Superior Tribunal Federal na Ação Penal 937, em maio de 2018 que restringiu a abrangência do foro privilegiado apenas aos crimes funcionais (SUPREMO TRIBUNAL FEDERAL, 2018).

Segundo Pinotti et al. (2019, p. 208) o foro privilegiado acabava funcionando como um escudo contra a responsabilização tend o em vista que os tribunais, estruturados para julgar recursos, ficavam responsáveis por conduzir as investigações ou ações penais sem estrutura adequada e abarrotado de julgamentos pendentes o que ocasionava lentidão processual.

Um importante mecanismo que pode ser implementado e incentivado em âmbito interno e que juntamente com os poderes e órgãos públicos fomenta a efetividade do sistema antilavagem nacional e internacional é a adoção de políticas de compliance nas atividades empresariais. Esse mecanismo revela-se importante especialmente para crimes de colarinho branco pois conforme analisa Gomes (apud SILVA, 2020, p.11) é justamente a falta de conhecimento dos delitos econômicos pela Justiça que reflete o alto índice da cifra negra e a lentidão do sistema.

Todos esses aspectos tem demonstrado no âmbito interno o esforço no enfrentamento a criminalidade, o qual através do auxílio direto pode ser reforçado e atingir resultados até então inatingíveis nacionalmente no contexto atual onde o dinheiro ilícito já não tem um paradeiro fixo, perpassando por diversas fronteiras e beneficiando-se de transações financeiras internacionais.

Vecchio e Vieira (2020, p.29) frisa a necessidade de pensar em mecanismos de cooperação que não sejam meros bancos de dados mas que concretizem aparatos de inteligência que cooperem não apenas na troca de informações mas tragam efetividade investigativa, administrativa e executiva.

Com o estudo dos mecanismos internos que cooperam de forma sistematizada com o auxílio direto verificamos que a rede de informações está atrelada a procedimentos públicos e privados, bem como orientações legislativas e jurisprudenciais que têm demonstrado a preocupação em garantir efetividade nas medidas contra o crime transnacional.

\section{O PROBLEMA CENTRAL DOS "PARAÍSOS FISCAIS"}

Apesar dos inúmeros esforços no combate à criminalidade moderna, não se pode fechar os olhos para Países que andam em rumo totalmente contrário, permitindo que grupos 
criminosos utilizem das facilidades burocráticas presentes em ordenamentos jurídicos e políticas econômicas. Tais Nações são usualmente conhecidas por "Paraísos Fiscais" e possuem em sua grande maioria as seguintes características segundo Magalhães (2018, p. 157-158):

1) A garantia de sigilo bancário absoluto ou de nível considera velmente elevado em comparação com os demais países no que concerne a titularidade de bens e recursos econômicos a loca dos nas instituições financeiras sediadas em seu território;

2) Ausência ou limitação exacerbada da cooperação judicial internaciona 1 , o que se perfaz pela não prestação ou pela prestação limita da de informações bancárias a outros países;

3) Facilidade legal-burocrática e baixo custo para criação de empresas off-shore ou shell companies, ainda que desprovidas de sede física no país;

4) Estabilidade política, social e econômica;

5) Existência de sistema bancário, meios de transporte e comunicação tecnologica mente desenvolvidos e conecta dos internacionalmente;

6) Ausência de controles cambiais, bem como não criminalização de delitos do colarinho branco, em especial, os financeiros e fiscais;

7) Oferta de serviços financeiros de utilidade agregada (ex.: assessoria contábil, jurídica e administrativa).

Mendroni (2018, p.236) citando reportagem do Jornal Brasil explica que a atratividade dos paraísos fiscais não é relacionada às vantagens fiscais, mas pelos benefícios decorrentes das regras lá aplicadas como o sigilo bancário, baixa supervisão de bancos e a escassa fiscalização de empresas com possibilidade inclusive de constituí-las sem identificação dos proprietários. Segundo Mendroni (2018, p. 240) para que o paraíso fiscal atraia a clientela de capitais das mais diversas partes do mundo ele oferece uma vasta gama de serviços incluindo "auxílio e assistência técnica necessária à ocultação dos dados, aplicações, ganhos e gestão jurídica local e contábil."

Embora não haja um passo a passo como regra para a lavagem de dinheiro, utilizada para trazer o ar de licitude aos valores provenientes de crimes, tais países notadamente dificultam as investigações pois permitem que o processo de lavagem se complete.

Segundo o Financial Action Task Force (GAFI ou FATF), organismo intergovernamental criado no âmbito da Organização para a Cooperação e Desenvolvimento Econômico (OCDE), existem 03 momentos para que o ciclo da lavagem se concretize e o dinheiro possa ser considerado "limpo": Colocação, Ocultação, Integração (BRASIL, 2020).

É através da primeira fase que o criminoso busca movimentar o dinheiro em países com regras permissivas com um sistema financeiro liberal. Feito isso, a segunda fase objetiva movimentar o dinheiro através de diversas transações para pessoas "laranjas" e empresas fictícias ou de fachada, preferencialmente valendo-se dos sigilos proporcionados novamente pelos paraísos fiscais. Por fim, na terceira fase, denominada Integração os ativos são 
formalmente incorporados no sistema econômico através de investimentos e serviços que facilitam a legitimação dos valores ilegais (BRASIL, 2020).

Além do mínimo controle exercido pelos paraísos fiscais Canestraro (2018, p. 6-7) chama a atenção a outro elemento visado pelos criminosos, a busca pelo anonimato através do sigilo bancário que figura como uma vantagem decorrente da confidencialidade dos investimentos independente da origem, inclusive as delitivas e fraudulentas. Canestraro (2018, p. 11) ressalta que em muitos casos o segredo bancário é utilizado como forma de entrave da cooperação entre os Estados, evidenciando inclusive que a OCDE considera uma prática fiscal desleal na medida que dificulta o controle e propicia a evasão fiscal.

Apesar do sigilo bancário ser um direito merecedor de proteção, sua flexibilização é medida excepcional que se impõe quando constata-se ser o impasse à persecução do crime de branqueamento de capitais (CANESTRARO, 2018, p.8).

Tal ponderação justifica-se ainda mais quando voltamos a atenção ao impacto que os crimes econômicos, normalmente antecedentes a lavagem de ativos, ocasionam em uma Nação. Bem observado por Pinotti et al. (2019, p. 16):

Corrupção mata. Mata na fila do atendimento pelo Sistema Único de Saúde, na falta de leitos, na escassez de medica mentos. Ma ta nas estra das sem manutenção adequada. A corrupção destrói vidas que não são educadas adequadamente, em razão da a usência de escolas e de deficiências de estruturas e equipamentos.

A macrodelinquência é um conceito que embora em constante evolução já pode ser entend ido como todo um aparato de condutas ilícitas graves com repercussão mundial que gera graves danos sociais à vítimas concretas ou difusas, estando entre eles os delitos econômicos, financeiros, tributários, previdenciários, ecológicos, imobiliários, lavagem de capitais, evasão de divisas, corrupção política entre outros. (GOMES apud SILVA, 2020, p.9)

Assim é preciso consolidar a ideia de que os paraísos físcais estão no centro da problemática de enfrentamento da microcriminalidade e enquanto houver a hipocrisia e tolerância de países desenvolvid os a efetividade esperad a pelos sistemas de controle e repressão não será alcançado (MAGALHÃES, 2018, p. 166).

Como forma de exercer pressão a tais países, estão as atividades do GAFI que entre outras funções promove políticas e edita recomendações sobre medid as de prevenção à lavagem de ativos, bem como avalia o cumprimento por parte de países membros e não-membros. Decorre do GAFI as principais orientações de controle preventivo voltadas para agentes econômicos e instituições financeiras, dentre as quais destaca-se: o dever de identificação dos 
clientes; dever de manter registro de operações pelo prazo mínimo de 5 anos e o dever de comunicação de transações financeiras suspeitas (MAGALHÃES, 2018, p. 153-154).

Países que não são cooperantes com as recomendações do GAFI são colocados em uma listagem, buscando encorajá-los a aderir aos padrões protetivos. No entanto, não havendo êxito na adequação das deficiências detectadas possibilita-se a tomada de medidas de alerta ou em último caso proibição de realização de transações entre os países membros com o Estado não-cooperante (MAGALHAES, 2018, p.155).

Oliveira (2018, p.2011) reconhece que o GAFI é o exemplo mais interessante que permite vislumbrar que o objetivo dos Estados é criar uma cooperação, reforçando a eficácia e aperfeiçoamento dos regimes de combate à lavagem de ativos. Portanto, o propósito não é inovar na criação novos procedimentos a cada assinatura de acordo internacional, mas promover a integração das ações estatais.

Percebe-se que a cooperação entre as diversas instituições públicas, através do compartilhamento de informações é um objetivo político que deve ser perseguid o caso pretenda que as investigações e repressão contra os crimes de colarinho branco alcancem alguma medida de efetividade (MORO, 2010, p. 131).

\section{CONSIDERAÇÕES FINAIS}

A criminalidade que marca o mundo contemporâneo globalizado é a macro criminalidade, caracterizada pelo contexto internacional, com vítimas difusas, afetação financeira de vários países e facilitada pelos meios tecnológicos.

A lavagem de dinheiro está inserida nesse contexto e suas principais características atuais com profissionais especializados, variedade de métodos e internacionalização das atividades, principalmente valendo-se de paraísos fiscais confirmam tal fato.

O reconhecimento desse panorama aliado a percepção de falhas e insuficiências nos métodos investigativos nacionais usualmente utilizados (delação premiada, gravação ambiental, ação controlada, interceptação telefônica e quebra de sigilo bancário) levaram os doutrinadores a defender regras probatórias compatíveis com as dificuldades, ou seja, para um crime transnacional, necessária uma persecução penal internacional.

Assim, para a efetivação do compartilhamento de provas entre Estados que possibilite um alcance mais apurado das investigações, foi necessário implementar um procedimento mais 
moderno que esteja apto a combater a lavagem de ativos e suas características atuais, principalmente que entendesse o volume do fenômeno que acontece em larga escala.

Advém então em 2015, no cenário nacional, junto ao novo Código de Processo Civil o Auxílio Direto que busca simplificar e agilizar a cooperação de forma direta entre as Autoridades Centrais de cada país que atuarão com base em tratados e convenções internacionais ou em regras de reciprocidade, buscando um colaborad or estrangeiro que execute os procedimentos solicitados conforme a regra de seu país e auxilie em qualquer medidajudicial ou extrajudicial necessária que não seja proibida pela lei brasileira.

O Auxílio direto é essencial na efetividade das ações de combate à criminalidade econômica principalmente porque ao permitir o avanço das investigações no âmbito internacional, além de facilitar na descoberta dos sujeitos ativos dos crimes, permite a localização e identificação de fundos ilícitos e obstrui a vantagem pecuniária decorrente dos ilícitos, ou seja, retira a compensação financeira do delito.

Apesar dos avanços nos últimos anos com o aprimoramento das técnicas e procedimentos investigativos, forçoso reconhecer o retrocesso que insiste em permanecer decorrente em grande parte dos benefícios aos criminosos estabelecidos pelos paraísos físcais e suas regras permissivas à lavagem de dinheiro.

Com isso, torna-se pacífico que o único caminho possível diante dessa realidade é reforçar o sistema institucional global formado por órgãos de proteção, prevenção e combate à criminalidade econômica no intuito de isolar tais países não cooperantes buscando em última medida a proibição de relacionamento financeiro com os demais Estados conforme medidas já orientadas pelo FATF - Financial Action Task Force.

\section{REFERÊNCIAS}

BRASIL. Constituição (1998). Emenda constitucional n. 9 , de 9 de novembro de 1995. Lex: legislação federal e marginalia, São Paulo, v. 59, p. 1966, out./dez. 1995.

BRASIL. Lei 13.105, de 16 de março de 2015. Código de Processo Civil. Diário Oficial da República Federativa do Brasil, Brasília, DF, 16 de março de 2015.

BRASIL. Lei 12.850, de 2 de agosto de 2013. Define organização criminosa e dispõe sobre a investigação criminal, os meios de obtenção da prova, infrações penais correlatas e o procedimento criminal; altera o Decreto-Lei ${ }^{\circ}{ }^{2}$.848, de 7 de dezembrode 1940 (Código Penal); revoga a Lei ${ }^{\circ}{ }^{9} .034$, de 3 de maio de 1995; e dá outras providências. Diário Oficial da República Federativa do Brasil, Brasília, DF, 2 de agosto de 2013. 
Brasil. Lei n ${ }^{\circ}$ 9.613, de 3 de março de 1998. Dispõe sobre os crimes de "lavagem" ou ocultação de bens, direitos e valores; a prevenção da utilização do sistema financeiro para os ilícitos previstos nesta Lei; cria o Conselho de Controle de Atividades Financeiras - COAF, e dá outras providências. 1998.

Brasil. Lei no 12.683, de 9 de julho de 2012. Altera a Lei no 9.613, de 3 de março de 1998, para tornar mais eficiente a persecução penal dos crimes de lavagem de dinheiro. 2012.

BRASIL. MINISTÉRIO DA ECONOMIA. Fases da lavagem de dinheiro. Disponível em: https://www.fazenda.gov.br/assuntos/prevencao-lavagem-dinheiro\#fases-da-lavagem-de-dinheiro Acesso em: 01 out. 2020.

BRASIL. MINISTÉRIO DA JUSTIÇA. Cooperação Jurídica Internacional em Matéria Penal. Disponível em: https://legado.justica.gov.br/sua-protecao/cooperacao-internacional/cooperacaojuridica-internacional-em-materia-penal Acesso em: 29 set. 2020a.

BRASIL. MINISTÉRIO DA JUSTIÇA. Roteiro de Tramitação do Auxílio Direto. Disponível em: https://legado.justica.gov.br/sua-protecao/cooperacao-internacional/cooperacao-juridica-internacionalem-materia-penal/roteiro-de-tramitacao Acesso em: 29 set. $2020 \mathrm{~b}$.

CALLEGARI, André Luís; WEBER, Ariel Barazzetti. Lavagem de dinheiro. São Paulo: Atlas, 2017.

CANESTRARO, Ana Carolina. Compartilhamento de dados e persecução do crime de branqueamento de capitais no âmbito dos paraísos financeiros. Revista de Estudos Jurídicos UNESP, Franca, ano 22, n. 35 , p. $135 \mathrm{jan} / \mathrm{jun}$.

GALÍCIA, Caique Ribeiro. Crime e Globalização: Reflexões sobre crimes transnacionais e a cooperação jurídica internacional na contemporaneidade. Revista Eletrônica de Direito Processual - REDP. Rio de Janeiro. Ano 12. Volume 19. Número 1. Janeiro a Abril de 2018. ISSN 1982 -7636. pp. 35-61. Disponível em: < https://www.e-publicacoes.ueri.br/index.php/redp/article/view/30184>. Acesso em: 06 jul. 2021. DOI: https://doi.org/10.12957/redp.2018.30184

LEMOS, Jordan Tomazelli Lemos. ZAGANELLI, Margareth Vetis. Cooperação Jurídica Internacional: Do Auxílio Direto na persecução de crimes de lavagem de capitais. Revista Jurídica Cesumar janeiro/abril 2018, v. 18, n. 1, p. 87-108 DOI: http://dx.doi.org/10.17765/2176-9184.2018v18n1p87108.

Disponível

em: https://periodicos.unicesumar.edu.br/index.php/revjuridica/article/view/6111/3183. Acesso em: 30 set. 2020

MAGALHÃES, Vlamir Costa. O crime de lavagem de ativos no contexto do Direito Penal Econômico Contemporâneo. Porto Alegre: Editora Nuria Fabris, 2018.

MENDRONI, Marcelo Batlouni. Crime de lavagem de dinheiro. São Paulo: Atlas, 2018.

MORIYAMA, Igor Mitsuo Sousa. O Sistema Probatório nos Crimes Penais Econômicos: Desafios, Limites e Possibilidades na Colheita de Provas. Disponível em: http://repositorio.ufla.br/jspui/handle/1/30756. Acesso em: 21 set. 2020

MORO, Sergio Fernando. Crime de lavagem de dinheiro. São Paulo: Editora Saraiva, 2010. OLIVEIRA, Marcos Vinicius Xavier de. A internacionalização do direito penal. Uma aproximação teórica a partir do crime de lavagem de capitais. Quaestio Iuris. vol. 11, $\mathrm{n}^{\circ} .01$, Rio de Janeiro, 2018. pp. 195-217. Disponível em: < https://www.epublicacoes.uerj.br/index.php/quaestioiuris/article/view/26248>. Acesso em: 06 Jul. 2021. DOI: 10.12957/rqi.2018.26248. 
PINOTTI et al. Corrupção: Lava Jato e Mãos Limpas - 1ª ed. - São Paulo: Portifolio-Penguin, 2019.

POLIDO, Fabrício Bertini Pasquot. Fundamentos, Estruturas e Mecanismos da Cooperação Jurídica Internacional e o Código de Processo Civil Brasileiro. Caderno Especial - Cooperação Jurídica Internacional. vol. 1. p. 37 - 82. Abr. 2018. DTR\2018\12621.

SILVA Eurison Ferreira da. A eficácia da cooperação penal internacional no combate ao crime de lavagem de dinheiro. Orientador: FIGUEIREDO, Carla Pedrosa de. 2018. 50f. Monografia (Graduação) - Curso de Direito Universidade Federal de Campina Grande Centro de Ciências Jurídicas e Sociais. Sousa, 2018.

SILVA, Hayalla Marcela Pontes da. Organizações criminosas transnacionais: a contribuição das off-shores para a lavagem de capitais e o papel dos acordos de cooperação internacionais no enfrentamento a esta prática. Orientador: ASSIS, Emerson Francisco de. 2019. 28f. Monografia (Graduação) - Curso de Direito Centro Universitário Tabosa de Almeida. Caruaru, 2019.

SILVA, Marcos Alves; SANTOS DE LIMA, Priscila Luciliene; SLONGO, Evelise. A expansão do direito penal. Relações Internacionais no Mundo Atual, [Curitiba], v. 4, n. 25, p. 299 - 316, maio 2020. ISSN 2316-2880. Disponível em: $\langle$ http://revista.unicuritiba.edu.br/index.php/RIMA/article/view/4112/371372454>. Acesso em: 07 jul. 2021. doi:http://dx.doi.org/10.21902/Revrima.v4i25.4112.

SOARES, Christiano Cordeiro; Carneiro, Gilberto Rodrigues y Onofre, Eduardo Gomes. Lavagem de dinheiro e o olhar jurídico: métodos administrativos de controle e prevenção. Revista Ciencias de la Documentación Vol: 6 num 1 (2020): 01-14. Disponível em: < http://cienciasdeladocumentacion.cl/gallery/art\%201\%20v016ene2020.pdf > . Acesso em: 07 jul. 2021.

SOBREIRA FILHO, Enoque Feitosa; REIS, Clayton; EMERICH, Beathrys Ricci. Direito regulatório específico: Controle pelo Banco Central do Brasil (BACEN) e pela Unidade de Inteligência financeira do Brasil na prevenão e combate á lavagem de dinheiro em instituições financeiras. Administração de Empresas em Revista, [Curitiba], v. 2, n. 16, p. 32 - 47, abr. 2019. ISSN 2316-7548. Disponível em: 〈http://revista.unicuritiba.edu.br/index.php/admrevista/article/view/4049 >. Acesso em: 06 jul. 2021.

SQUEFF, Tatiana de Almeida F. R. Cardoso. Para além da cooperação tradicional: A positivação do auxílio direto no novo código de processo civil. Revista de Direito Constitucional e Internacional. Vol. 100/2017. p. 261-300. Mar-Abr. 2017. DTR12017\695.

SUPREMO TRIBUNAL FEDERAL, Ação Penal 937. Questão de Ordem em Ação Penal. Limitação do foro por prerrogativa de função aos crimes praticados no cargo e em razão dele. Rel. Min. Roberto Barroso, Tribunal Pleno. Divulgação 03/05/2018. Publicação 11/12/2018.

VECCHIO, Fabrizio Bom; VIEIRA, Debora Manke. Compliance Tributário e o Crime de Lavagem de Dinheiro: Análise Legal das Medidas Éticas e Sancionatórias. J2 - Jornal Jurídico, v. 2 n. 2 (2019). Publicado 2020. Disponível em: < https://revistas.ponteditora.org/index.php/j2/article/view/220 . Acesso em 06 jul. 2021. DOI: https://doi.org/10.29073/j2.v2i2

ZANON, Patricie Barricelli. Políticas Públicas de Controle da Corrupçãoe da Lavagem de Dinheiro no Brasil: Um Panorama Institucional. Orientador: Marco Aurélio Pinto Florêncio Filho. 2019. 139f. Dissertação (Mestrado Político e Econômico) - Universidade Presbiteriana Mackenzie. São Paulo, 2019. 